\title{
Phenethyl isothiocyanate reduces breast cancer stem cell-like properties by epigenetic reactivation of CDH1
}

\author{
TAOLAN ZHANG ${ }^{1-4}$, WEIJUAN ZHANG $^{3}$ and MENG HAO ${ }^{4}$ \\ ${ }^{1}$ Department of Pharmacy, The First Affiliated Hospital, University of South China, Hengyang, Hunan 421001, P.R. China;
${ }^{2}$ Department of Pharmacology and Toxicology, Indiana University School of Medicine, Indianapolis, IN 46202, USA;
${ }^{3}$ Institute of Pharmacy and Pharmacology, University of South China, Hengyang, Hunan 421001; ${ }^{4}$ Department of
Executive Management, The First Affiliated Hospital, University of South China, Hengyang, Hunan 421001, P.R. China
}

Received June 5, 2020; Accepted October 20, 2020

DOI: $10.3892 /$ or.2020.7860

\begin{abstract}
Breast cancer is the most frequently diagnosed malignancy and leading cause of cancer-related deaths among women worldwide. Tumor recurrence, or metastasis, is caused by cancer stem cells and has a dismal prognosis for breast cancer patients. Thus, targeting breast cancer stem cells (BCSCs) for eradication is a potential method to improve clinical outcomes. Phenethyl isothiocyanate (PEITC) is a novel epigenetic regulator derived from cruciferous vegetables that has marked antitumor effects. However, the exact mechanism of these antitumor effects by PEITC is unknown. As breast cancer progresses, a tumor suppressor in the breast, cadherin 1 (CDH1), is silenced by hypermethylation of the promoter region, further promoting the stem cell-like properties of cancer. Herein, the ability of PEITC to reduce BCSC-like properties by epigenetic reactivation of $\mathrm{CDH} 1$ was investigated by multiple analyses such as MTT, colony formation and sphere formation assays, methylation-specific PCR, western blot analysis, Co-IP and qPCR. It was revealed that PEITC inhibited colony and mammosphere formation and decreased the expression of protein markers associated with BCSC-like properties via epigenetic reactivation of CDH1. Further exploration of this mechanism revealed inhibitory effects of PEITC on DNMTs and HDACs, which play a pivotal role in demethylating the hypermethylated $\mathrm{CDH} 1$ promoter region. Reactivated $\mathrm{CDH} 1$ suppressed the $\mathrm{Wnt} / \beta$-catenin pathway which confers BCSC-properties in breast cancer cells. These findings suggest a novel method to eradicate BCSCs from breast cancer patients.
\end{abstract}

Correspondence to: Dr Taolan Zhang, Department of Pharmacy, The First Affiliated Hospital, University of South China, Hengyang, Hunan 421001, P.R. China

E-mail: csu_ztl@163.com

Key words: phenethyl isothiocyanate, breast cancer stem cell, epigenetic regulation, cadherin $1, \mathrm{Wnt} / \beta$-catenin pathway

\section{Introduction}

Breast cancer is the most frequently diagnosed malignancy and leading cause of cancer-related deaths among women on a global scale. Data from the International Agency for Research on Cancer (IARC), a World Health Organization agency, indicated that in 2018 there were more than 2,088,849 new cases of breast cancer and approximately 626,679 breast cancer-related deaths in women (1). Therefore, breast cancer is a global health issue of women that must be addressed. There are five primary treatment options, most of which include a combination of: surgery, radiation, chemotherapy, hormone therapy and targeted therapies (2). Despite recent advances in breast cancer treatments, a subgroup of breast cancer cells, termed breast cancer stem cells (BCSCs), often cause tumor recurrence and metastasis in 30-40\% of early-stage breast cancer patients following treatment (3). The BCSC characteristics of heterogeneity, self-renewal, and pluripotency lead to malignant progression, treatment resistance and a poor clinical prognosis (4). Recent studies have revealed that several signaling pathways for maintaining self-renewal and differentiation such as Wnt, Notch and Hedgehog are excessively activated in BCSCs (5). Additionally, multidrug resistance and DNA repair genes including multidrug resistance-1 (MDR1) and Rad 51 are overexpressed in BCSCs, conferring resistance to conventional chemotherapeutic drugs and radiotherapies $(6,7)$. Moreover, BCSCs can promote angiogenesis and grow in an anchorage-independent manner that contributes to cancer dissemination and secondary tumors (8). These key activities of BCSCs in breast carcinogenesis suggest that devising novel methods to eradicate BCSCs may improve the poor prognosis of recurrent or metastatic breast cancer patients.

Phenethyl isothiocyanate (PEITC), one of the major bioactive compounds derived from cruciferous vegetables such as broccoli, watercress and Brussels sprouts, possesses marked anticancer activities by inhibiting cell cycle progression, inducing apoptosis and reversing drug resistance (9). Recent studies have revealed that PEITC is selectively lethal for malignant cells with reduced cytotoxicity for normal cells (10-12), suggesting that it has potential as a 'high-efficiency and lower toxicity' chemotherapy drug. At present, clinical trials are evaluating PEITC including 'The Safety and Efficacy Test 
of Nutri-PEITC Jelly in Head and Neck Cancer Patients' (NCT03034603) and 'Phenethyl isothiocyanate in Preventing Lung Cancer in Smokers' (NCT00691132). Moreover, a completed phase I study (NCICN-55120) has revealed PEITC antitumor activity at micromolar concentrations, further indicating its promise for clinical use (13). In recent years, epigenetic silencing of tumor suppressor genes during the initiation and progression of cancers, including breast cancer, has been established $(14,15)$. Emerging evidence further indicates that epigenetic regulation, including DNA hypermethylation, plays a pivotal role in promoting cancer stem cell characteristics $(16,17)$. As such, DNA hypermethylation and histone deacetylation have been hypothesized to be effective targets for cancer treatments, including the eradication of cancer stem cells (CSCs) (18). PEITC is a novel epigenetic regulator that inhibits both DNA methyltransferases (DNMTs) and histone deacetylases (HDACs), both of which mediate the silencing of tumor suppressor genes during tumor progression $(19,20)$. However, no study to date has explored the mechanism by which PEITC epigenetically reactivates tumor suppressor genes to eradicate BCSCs.

The cadherin $1(\mathrm{CDH} 1)$ gene is located at chromosome 16q22.1 and encodes a transmembrane glycoprotein called E-cadherin, which functions as a tumor suppressor by maintaining cell adhesion and adherent junctions in normal tissues (21). The expression of CDH1 is frequently observed to be silenced in solid malignant tumors, including breast cancer, due to DNA hypermethylation of the promoter region during tumor initiation and progression $(16,22)$. Previous studies have revealed that a loss of $\mathrm{CDH} 1$ expression in breast cancer can initiate the epithelial-mesenchymal transition (EMT) and is associated with metastasis and poor prognosis $(23,24)$. Recent studies have also reported that demethylation of the CDH1 promoter region to restore $\mathrm{CDH} 1$ expression inactivates the Wnt/ $\beta$-catenin pathway and suppresses carcinoma cell stemness (16), indicating another potential way to eradicate BCSCs.

In summary, PEITC functions as an epigenetic regulator and CDH1 is silenced by DNA hypermethylation. Additionally, following histone deacetylation in breast cancer, the $\mathrm{Wnt} / \beta$-catenin pathway is activated to maintain cancer stem cell-like properties. The purpose of the present study was to examine the effects of PEITC on the CSC-like properties of breast cancer cells and elucidate the mechanisms.

\section{Materials and methods}

Cell culture and drugs. Human breast cancer cell lines MCF-7 and MDA-MB-231 were obtained from the American Type Culture Collection. These cell lines were cultured at $37^{\circ} \mathrm{C}$ under a $5 \% \mathrm{CO}_{2}$ atmosphere in Dulbecco's modified Eagle's medium (DMEM) supplemented with $10 \%$ fetal bovine serum and propagated for $<8$ generations after resuscitation. Reagents, including PEITC, Aza-deoxycytidine (5-Aza), and Trichostatin A (TSA) were purchased from Sigma-Aldrich (Merck KGaA).

MTT assay. Three thousand viable breast cancer cells (MCF-7 and MDA-MB-231) were plated onto a 96-well plate (Corning, Inc.) in triplicate for $24 \mathrm{~h}$, and then treated with various concentrations of PEITC $(0,1,2,5,10,25,50$ and $100 \mu \mathrm{M})$ dissolved in complete medium and cultured at $37^{\circ} \mathrm{C}$ under a $5 \% \mathrm{CO}_{2}$ atmosphere for $72 \mathrm{~h}$. Cells were then incubated with $100 \mu 1$ of 3-(4,5-dimethylthiazol-2-yl]-2,5-diphenyltetrazolium bromide) (MTT) solution $(0.5 \mathrm{mg} / \mathrm{ml})$ for $4 \mathrm{~h}$ at $37^{\circ} \mathrm{C}$ in the dark. The MTT solution was then discarded and the formazan was solubilized in $100 \mu \mathrm{l}$ DMSO for $1 \mathrm{~h}$ on a shaker. The optical density was measured at $570 \mathrm{~nm}$ using SpectraMax M Series Multi-Mode Microplate Reader (Molecular Devices, LLC).

Colony formation assay. Three hundred viable breast cancer cells (MCF-7 and MDA-MB-231) were inoculated into a 6-well plate (Corning, Inc.) in triplicate for $24 \mathrm{~h}$, then incubated with $0.1 \%$ DMSO (control) or PEITC (5 or $10 \mu \mathrm{M}$ ) and dissolved in complete medium cultured at $37^{\circ} \mathrm{C}$ under a $5 \% \mathrm{CO}_{2}$ atmosphere for 10 days. The colonies were fixed with a fixation solution (acetic acid:methanol, 1:7) for 5 min and stained with $0.5 \%$ crystal violet for $20 \mathrm{~min}$ at room temperature. The stained colonies were washed 3 times with PBS and counted with a countermark pen. Colonies with a minimum cell number $>50$ observed under an inverted phase-contrast microscope (Nikon Corporation) were included in the final statistical analysis. The images of the colonies presented were visualized using a Canon scanner (CanoScan 5600F).

Sphere formation assay. Breast cancer Cells (MCF-7 and MDA-MB-231) were seeded in 6-well ultra-low cluster plates (Corning, Inc.) at a density of $5 \times 10^{3}$ cells and cultured at $37^{\circ} \mathrm{C}$ under a $5 \% \mathrm{CO}_{2}$ atmosphere in CSC enrichment medium including DMEM/F12 serum-free medium, 2\% B27, $20 \mathrm{ng} / \mathrm{ml}$ epidermal growth factor (EGF), and $20 \mathrm{ng} / \mathrm{ml}$ recombinant human fibroblast basic growth factor (RH-bFGF) (all from Gibco; Thermo Fisher Scientific, Inc.). Cells were treated with either PEITC at 5 or $10 \mu \mathrm{M}$ or $0.1 \%$ DMSO as the vehicle control. After 7 days, the number of tumor spheres $(\geq 50 \mu \mathrm{m})$ was imaged and counted under an inverted phase-contrast microscope (Nikon Corporation) at a magnification of x100.

Methylation-specific PCR (MSP). Breast cancer cells (MCF-7 and MDA-MB-231) were seeded in 6-well plates (Corning, Inc.) at a density of $2 \times 10^{5}$ cells in triplicate for $24 \mathrm{~h}$, then incubated with $0.1 \%$ DMSO (control) or PEITC $(5$ or $10 \mu \mathrm{M})$ or positive control epigenetic-regulating drugs $(2.5 \mu \mathrm{M} 5$-Aza and $0.5 \mu \mathrm{M}$ TSA) for 5 days at $37^{\circ} \mathrm{C}$ under a $5 \% \mathrm{CO}_{2}$ atmosphere. Genomic DNA was isolated from treated cells using the QIAamp DNA Mini Kit (Qiagen, Inc.). Next, $1 \mu \mathrm{g}$ of genomic DNA was denatured by bisulfite conversion with the EZ DNA Methylation Gold Kit (Zymo Research Corp.) following the manufacturerss instructions and then used as a template for PCR amplification. The primer pairs used for methylated $\mathrm{CDH} 1$ were: forward, 5'-TAACTACAACCAAATAAACCCCG-3' and reverse, 5'-TCGAATTTAGTGGAATTAGAATCGT-3'. The primer pairs used for unmethylated E-cadherin were: forward, 5'-TAACTACAACCAAATAAACCCCAAA-3' and reverse, 5'-TTGAATTTAGTGGAATTAGAATTGT-3'. The PCR cycling conditions consisted of an initial denaturation at $95^{\circ} \mathrm{C}$ for $2 \mathrm{~min}$, followed by 30 cycles of denaturation at $95^{\circ} \mathrm{C}$ for $1 \mathrm{~min}$, annealing at $50^{\circ} \mathrm{C}$ for $1 \mathrm{~min}$, and extension at $74^{\circ} \mathrm{C}$ for $2 \mathrm{~min}$. The amplification products were separated 
on a $1.5 \%$ agarose gel by electrophoresis and visualized using ethidium bromide staining and a Gel Documentation 2000 system (Bio-Rad Laboratories, Inc.). The band densities were quantified using ImageJ software (version 1.52; National Institutes of Health).

Western blot analysis. Cells were lysed in ice-cold RIPA lysis buffer (50 mM Tris-HCl, pH 7.4, 150 mM NaCl, 1 mM EDTA, $1 \mathrm{mM}$ dithiothreitol, $1 \%$ Triton-X-100 and $0.1 \%$ sodium deoxycholate sulfate) supplemented with phosphatase inhibitor $\left(\mathrm{Na}_{3} \mathrm{Vo}_{4}, 1 \mathrm{mM}\right)$ and protease inhibitor (phenylmethylsulfonyl fluoride, $1 \mathrm{mM}$ ). The cell lysate was then centrifuged at $12,000 \mathrm{x} g$ for $10 \mathrm{~min}$ at $4^{\circ} \mathrm{C}$. The Pierce ${ }^{\mathrm{TM}}$ Rapid Gold bicinchoninic acid (BCA) kit (Thermo Fisher Scientific, Inc.) was used to measure protein concentrations. Proteins (20-50 $\mu \mathrm{g}$ per lane) were then separated by electrophoresis on an SDS-PAGE gel (6 or 12\%) and transferred onto a Sequi-Blot ${ }^{\mathrm{TM}}$ PVDF membrane (Bio-Rad Laboratories, Inc.). Then, the membranes were blocked by $5 \%$ milk in TBST (Tris base- $0.1 \%$ Tween-20) at room temperature for $2 \mathrm{~h}$. Antibodies to c-Myc (D84C12; rabbit mAb; product no. 5605), ALDH-1 (D9J7R; XP ${ }^{\circledR}$ rabbit mAb; product no. 36671), Oct-4A (C30A3; rabbit mAb; product no. 2840), Sox-2 (D6D9; $\mathrm{XP}^{\circledR}$ rabbit $\mathrm{mAb}$; product no. 3579), phospho- $\beta$-catenin (Ser675) (D2F1XP ${ }^{\circledR}$; rabbit mAb; product no. 4176), phospho- $\beta$-catenin (Ser33/37) (rabbit mAb; product no. 2009), cyclin D1 (E3P5S; $\mathrm{XP}^{\circledR}$ rabbit mAb; product no. 55506), and CDH1 (mouse mAb; product no. 14472) were obtained from Cell Signaling Technology, Inc. and diluted 1:1,000 for binding with target proteins overnight at $4^{\circ} \mathrm{C}$. Antibodies against Dnmt1 (mouse mAb; cat. no. sc-514784), Dnmt3a (mouse mAb; cat. no. sc-365769), Dnmt3b (mouse $\mathrm{mAb}$; cat. no. sc-81252), HDAC1 (mouse mAb; cat. no. sc-81598), and HDAC2 (mouse mAb; cat. no. sc-9959) were purchased from Santa Cruz Biotechnology, Inc. and diluted 1:200 for binding with target proteins overnight at $4^{\circ} \mathrm{C}$. $\beta$-actin (mouse mAb; product no. A1978) and secondary anti-mouse (product no. A2429) or anti-rabbit (product no. A3937) antibodies were obtained from Sigma-Aldrich (Merck KGaA) and diluted 1:1,000 for binding with target proteins for $2 \mathrm{~h}$ at room temperature. After washing the membranes with TBST (Tris base- $0.1 \%$ Tween-20) 3 times, protein bands were imaged with enhanced chemiluminescence (Thermo Fisher Scientific, Inc.) and an X-ray film system (Ece Scientific Co., Inc). The band densities were quantified using ImageJ software (version 1.52; National Institutes of Health).

Co-immunoprecipitation (Co-IP). Cells were lysed for $30 \mathrm{~min}$ in ice-cold immunoprecipitation (IP) lysis buffer for IP (40 mM HEPES, 0.3\% Chaps, 2 mM EDTA, $1 \mathrm{mM}$ dithiothreitol, $10 \mathrm{mM}$ pyrophosphate, $10 \mathrm{mM} \beta$-glycerophosphate, and $50 \mathrm{mM} \mathrm{NaF}$ ) supplemented with phosphatase inhibitor $\left(\mathrm{Na}_{3} \mathrm{Vo}_{4}, 1 \mathrm{mM}\right)$ and protease inhibitor (phenylmethylsulfonyl fluoride, $1 \mathrm{mM}$ ). The supernatant was collected after centrifugation at $4^{\circ} \mathrm{C}$ at $13,000 \mathrm{x}$ for $30 \mathrm{~min}$ and the total protein concentration was adjusted to $1 \mu \mathrm{g} / \mu \mathrm{l}$. Finally, $200 \mu \mathrm{g}$ of total protein was used per IP reaction. The dilution rate of the CDH1 antibody (mouse mAb; product no. 14472; Cell Signaling Technology) was 1:50 per IP reaction. The protein G agarose magnetic beads (Santa Cruz Biotechnology, Inc.) were prepared according to the manufacturer's instructions. The bead-bound immune complexes were incubated with rotation for $4 \mathrm{~h}$ at $4^{\circ} \mathrm{C}$ and then the beads were pelleted using a magnetic separation rack and washed with $500 \mu 1$ of $1 \mathrm{X}$ cell lysis buffer five times (keeping on ice between washes). The bead-bound immune complexes were resuspended in $30 \mu \mathrm{l}$ of 1X SDS-PAGE loading buffer and incubated for $5 \mathrm{~min}$ on a heating block at $95^{\circ} \mathrm{C}$ to denature and release proteins. Finally, the magnetic beads were removed using the magnetic separator and the supernatant was transferred to a clean $1.5 \mathrm{ml}$ tube for western blotting.

$R N A$ isolation and $R T-q P C R$. Total RNAs were isolated from MCF-7 and MDA-MB-231 cells using TRIzol Reagent (Thermo Fisher Scientific, Inc.) and the concentration was measured by Nanodrop (BioSpec-nano; Shimadzu Corporation). SuperScript $^{\mathrm{TM}}$ III Reverse Transcriptase (Thermo Fisher Scientific, Inc.) was used for reverse transcription and RT-qPCR was performed with Platinum SYBR-Green qPCR SuperMix-UDG (Thermo Fisher Scientific, Inc.) on an ABI PRISM $^{\circledR} 7000$. The comparative Cq method $\left(2^{-\Delta \Delta C q}\right)$ (25) was used to analyze the data and GAPDH mRNA expression was used as the normalization control. The CDH1 primers were: forward, 5'-TGGGTTATTCCTCCCATCAG-3' and reverse, 5'-GTCACCTTCAGCCATCCTGT-3'. The GAPDH primers were: forward, 5'-AGGTCGGAGTCAACGGATTTG-3' and reverse, 5'-GTGATGGCATGGACTGTGGT-3'. The PCR cycling conditions consisted of an initial denaturation at $94^{\circ} \mathrm{C}$ for $2 \mathrm{~min}$, followed by 30 cycles of denaturation at $94^{\circ} \mathrm{C}$ for $1 \mathrm{~min}$, annealing at $60^{\circ} \mathrm{C}$ for $1 \mathrm{~min}$, and extension at $72^{\circ} \mathrm{C}$ for $2 \mathrm{~min}$.

Statistical analyses. GraphPad Prism 5 software (GraphPad Software, Inc.) was used to conduct the statistical analyses. All data were expressed as the mean \pm standard deviation (SD) except where indicated. One-way ANOVA with Dunnett's multiple comparison test or two-tailed unpaired Student's $\mathrm{t}$-test was used to compare means between groups as indicated. $\mathrm{P}<0.05$ or a fold change $>2$ was considered to indicate a statistically significant difference.

\section{Results}

Selection of PEITC concentrations. Typically, sublethal doses of a compound are used to investigate epigenetic regulation properties in vitro (26). We performed a preliminary experiment to evaluate the effects of PEITC at 0, 1, 2, 5, 10, 25, 50 and $100 \mu \mathrm{M}$ on the cell viability of MCF-7 and MDA-MB-231 cells using an MTT assay. PEITC at 5 and $10 \mu \mathrm{M}$ significantly inhibited the growth of breast cancer cells after treatment for $72 \mathrm{~h}$, but it did not markedly induce cell death (data not shown). Thus, 5 and $10 \mu \mathrm{M}$ PEITC were used to evaluate the epigenetic effects of PEITC on breast cancer cells in vitro.

PEITC reduces colony and sphere formation abilities. Colony and sphere formation assays are two methods frequently used to identify cancer stem cells (CSCs) and study their properties in vitro (27). To evaluate the effects of PEITC on the colony formation ability of breast cancer cells, MCF-7 and MDA-MB-231 cells were seeded at 300 cells/well in 6-well dishes. Cells were treated with PEITC (5 and $10 \mu \mathrm{M})$ 


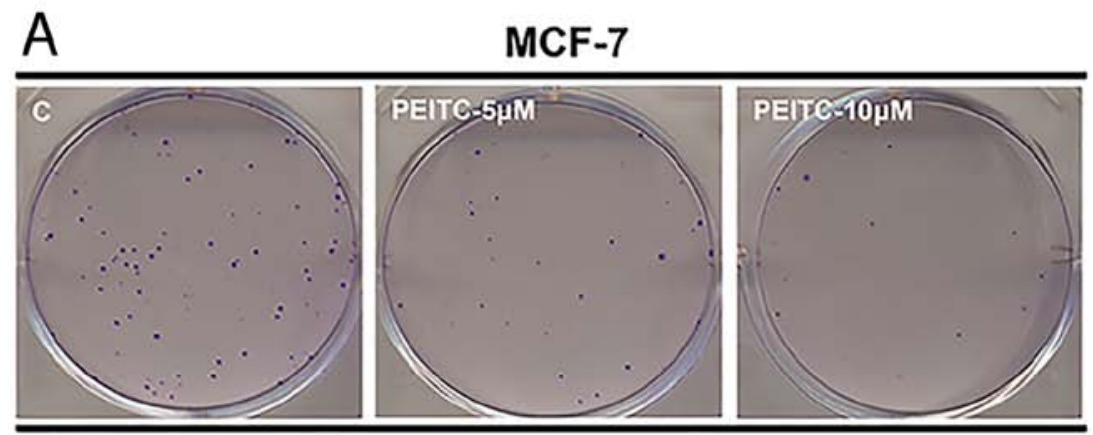

$\mathrm{B}$
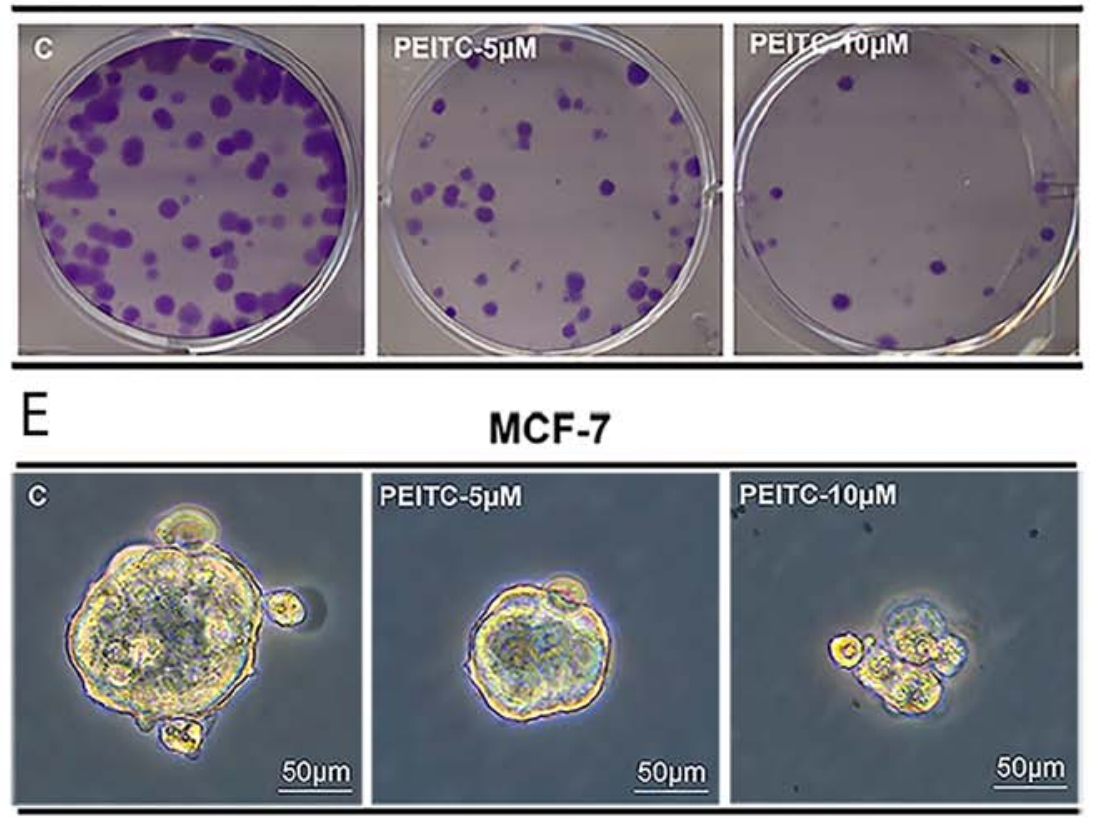

$\mathrm{F}$

MDA-MB-231
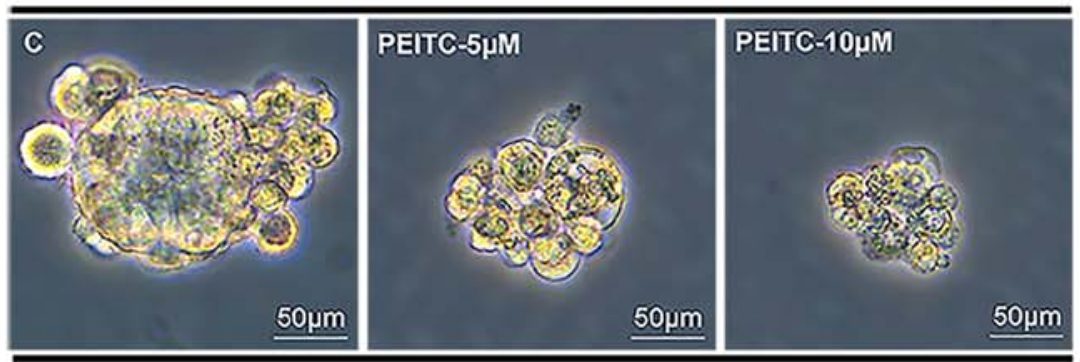

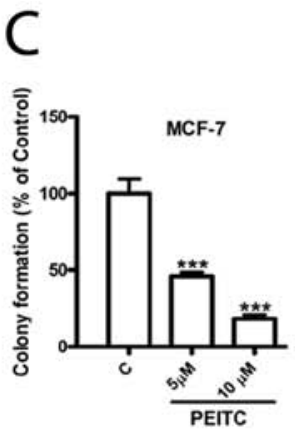

D

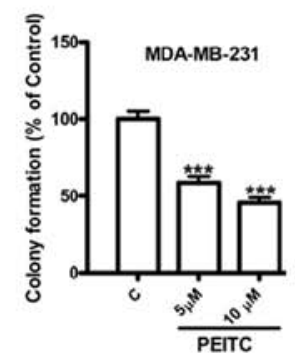

G

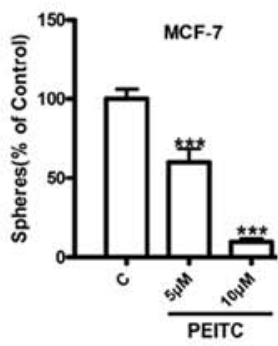

$\mathrm{H}$

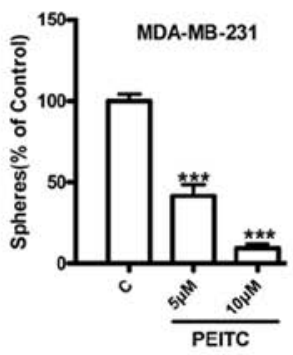

Figure 1. Effect of PEITC on colony and sphere formation abilities in breast cancer cells. Representative images revealed the suppression of colony formation abilities by PEITC in (A) MCF-7 and (B) MDA-MB-231 cells. Bar graphs quantified the reduction in the colony counts for (C) MCF-7 and (D) MDA-MB-231 cells by PEITC. Representative images revealed the inhibition of sphere formation in (E) MCF-7 and (F) MDA-MB-231 cells by PEITC (scale bar, $50 \mu \mathrm{m}$ ). Bar graphs quantified the reduction in the number of spheres in (G) MCF-7 and (H) MDA-MB-231 cells by PEITC. Data were presented as the mean \pm SD, $n=3$. ${ }^{* * * *} \mathrm{P}<0.001$ vs. the control. PEITC, phenethyl isothiocyanate; $\mathrm{C}$, control.

or $0.1 \%$ DMSO (control) for 10 days. PEITC at 5 and $10 \mu \mathrm{M}$ significantly reduced the number of MCF-7 colonies to 45 and $20 \%$ (Fig. 1A and C) and MDA-MB-231 colonies to 60 and $45 \%$ (Fig. 1B and D), respectively. In the sphere formation assay, MCF-7 and MDA-MB-231 cells were dissociated into single cells, seeded into ultra-low cluster 6-well plates and treated with PEITC (5 and $10 \mu \mathrm{M}$ ) or $0.1 \%$ DMSO (control) in CSC enrichment medium. After seven days, it was observed that PEITC (5 and $10 \mu \mathrm{M})$ significantly decreased the size of MCF-7 and MDA-MB-231 mammospheres (Fig. 1E and F) and reduced the number of mammospheres to 60 and $10 \%$ in MCF-7 cells (Fig. 1G) and 40 and 10\% in MDA-MB-231 (Fig. 1H).

PEITC suppresses the expression of BCSC-related proteins. Previous studies have identified that the protein expression levels of c-Myc, ALDH-1, Oct-4A and Sox-2 are associated with BCSC-like properties (28-31). Since PEITC could reduce the colony and sphere formation abilities of breast cancer cells, it was hypothesized that BCSC-related proteins 

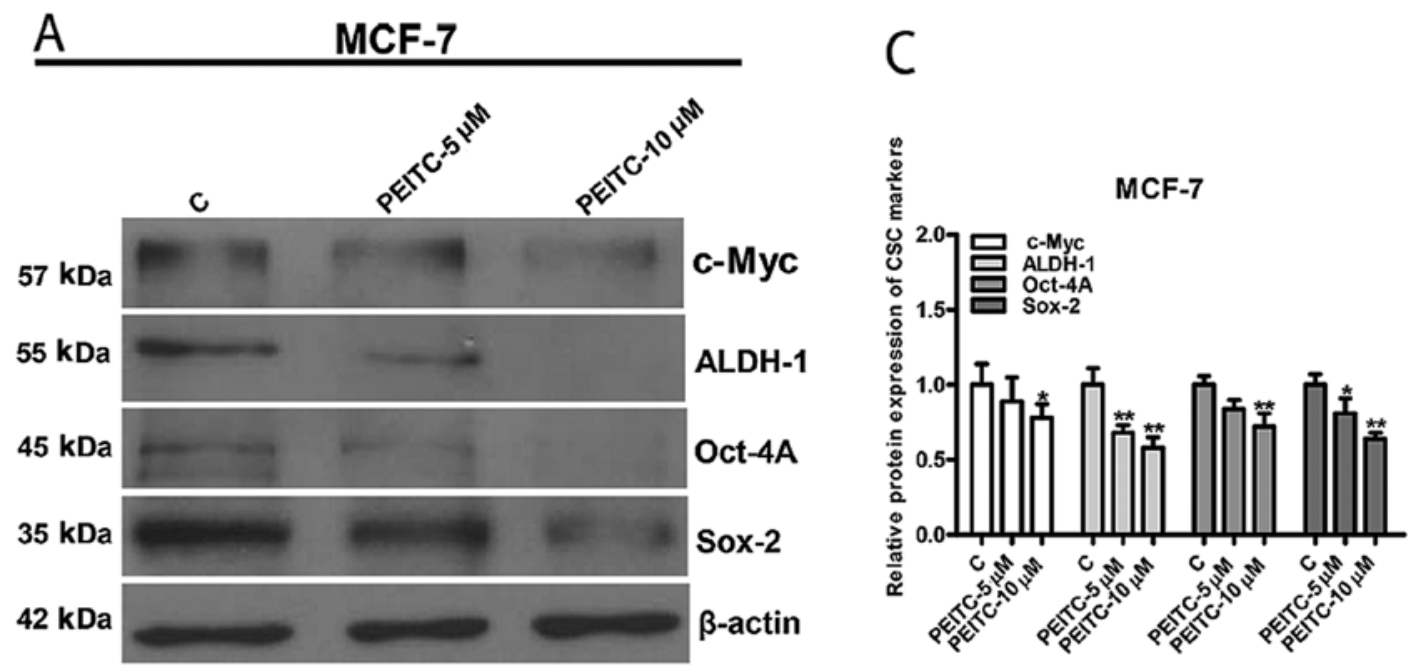

B $\quad$ MDA-MB-231

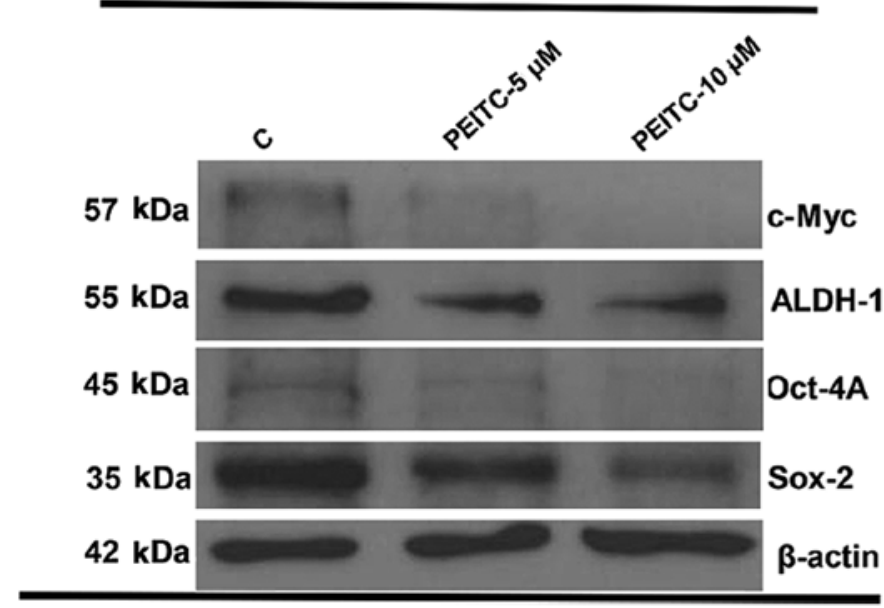

D

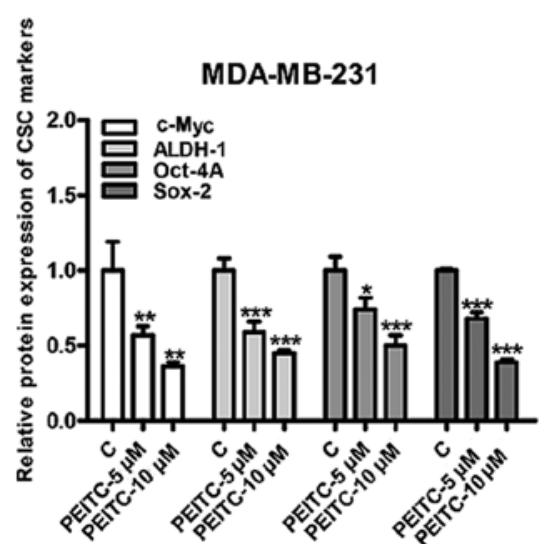

Figure 2. Effect of PEITC on BCSC-associated protein markers. c-Myc, ALDH-1, Oct-4A and Sox-2 are BCSC-associated protein markers. Representative western blots revealed the reduction in the protein expression of c-Myc, ALDH-1, Oct-4A and Sox-2 by PEITC treatment in (A) MCF-7 and (B) MDA-MB-231 cells. Bar graphs of quantitative densitometry indicated the downregulation of c-Myc, ALDH-1, Oct-4A, and Sox-2 in (C) MCF-7 and (D) MDA-MB-231 cells Data were presented as the mean $\pm \mathrm{SD}, \mathrm{n}=3 .{ }^{*} \mathrm{P}<0.05,{ }^{* *} \mathrm{P}<0.01$ and ${ }^{* * *} \mathrm{P}<0.001$ vs. the control. PEITC, phenethyl isothiocyanate; BCSC, breast cancer stem cell; CSC, cancer stem cell; C, control

may also be downregulated. To test our hypothesis, western blotting and quantitative densitometry with ImageJ were used to observe the protein expression of c-Myc, ALDH-1, Oct-4A and Sox-2. All targeted BCSC-related proteins were downregulated in both MCF-7 (Fig. 2A and C) and MDA-MB-231 cells (Fig. 2B and D) following PEITC (5 and $10 \mu \mathrm{M})$ treatment for 3 days.

PEITC restores $\mathrm{CDH1}$ expression by demethylation of the promoter region. The hypermethylation of the $\mathrm{CDH} 1$ promoter region has been identified in numerous malignant cancers including breast cancer, leading to its encoded metastasis suppressor, E-cadherin, being silenced along with cancer progression (32). Recent studies have revealed that epigenetic silencing of the CDH1 gene contributes to CSC-like properties (16). Moreover, PEITC has been identified as a new epigenetic regulator that can demethylate the hypermethylated promoter regions of tumor suppressor genes to eliminate cancer cells (19). Therefore, it was hypothesized that PEITC reduces BCSC-like properties via epigenetic reactivation of $\mathrm{CDH} 1$. To test our hypothesis, we first examined the extent of methylation of the CDH1 promoter region in the presence of either $0.1 \%$ DMSO (control) or PEITC (5 or $10 \mu \mathrm{M}$ ) or positive control epigenetic regulating drugs $(2.5 \mu \mathrm{M}$ 5-Aza and $0.5 \mu \mathrm{M}$ TSA) for 5 days. Methylation-specific PCR (MSP) and quantitative analysis revealed high methylation levels of the $\mathrm{CDH} 1$ promoter region in untreated breast cancer cells, suggesting hypermethylation of the $\mathrm{CDH} 1$ promoter. However, a significant increase in the unmethylation of the CDH1 promoter region was observed in PEITC $(5$ or $10 \mu \mathrm{M})$, 5-Aza $(2.5 \mu \mathrm{M})$, and TSA $(0.5 \mu \mathrm{M}) \mathrm{MCF}-7$ (Fig. 3A and C) and MDA-MB-231 (Fig. 3B and D) treated-cells compared to the control. The change in mRNA and protein levels of CDH1 in MCF-7 and MDA-MB-231 cells following treatment with either PEITC (5 or $10 \mu \mathrm{M})$ and 5-Aza $(2.5 \mu \mathrm{M})$ and TSA $(0.5 \mu \mathrm{M})$ for 5 days was further analyzed using qPCR and western blotting, respectively. PEITC significantly enhanced CDH1 mRNA expression in both MCF-7 (Fig. 3E) 

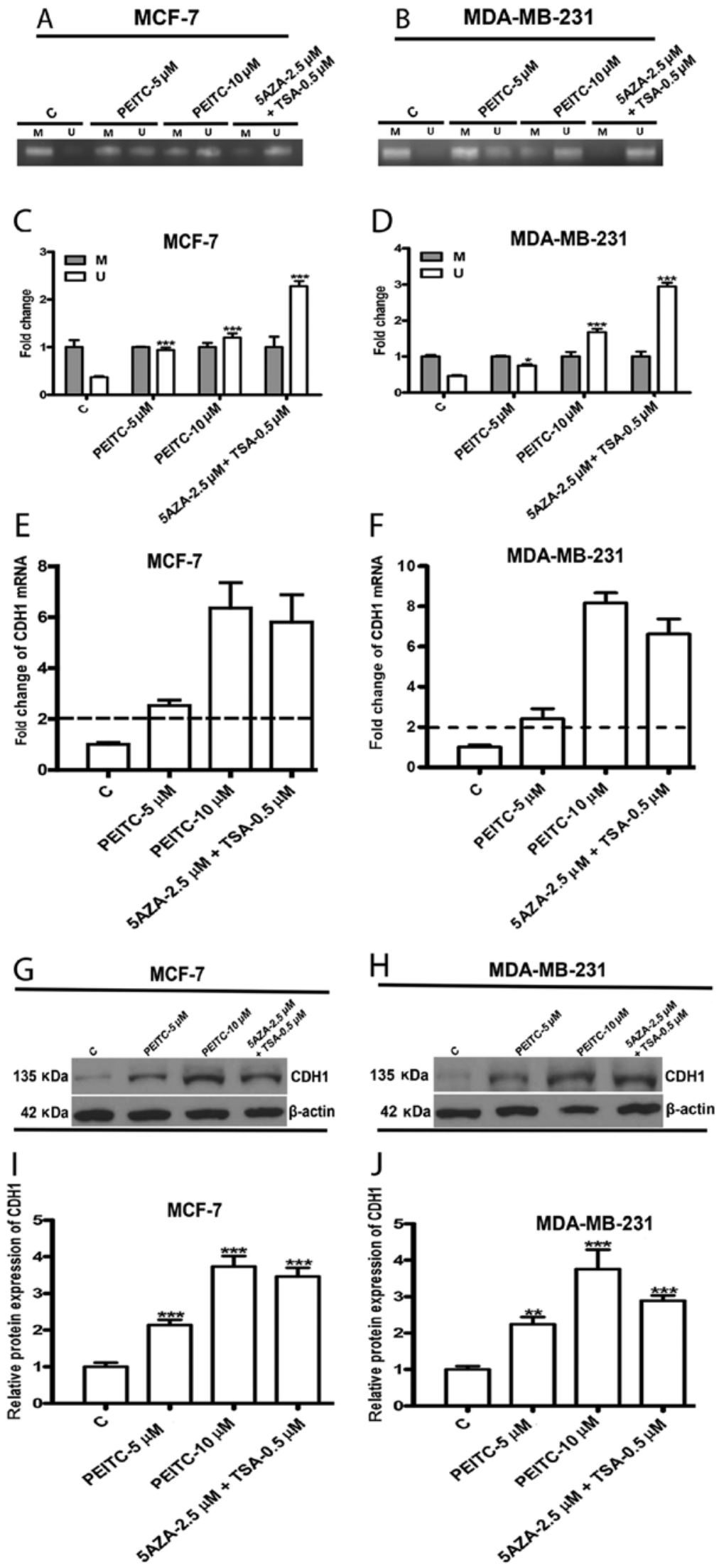

Figure 3. Effect of PEITC on CDH1 promoter methylation. Representative MSP bands revealed the decrease of methylation and increase of unmethylation in the $\mathrm{CDH} 1$ promoter region of (A) MCF-7 and (B) MDA-MB-231 cells by the indicated treatments. Bar graphs of the relative intensity of MSP bands quantified the change in unmethylation (normalized to the corresponded methylated band) of the CDH1 promoter region in (C) MCF-7 and (D) MDA-MB-231 cells following the indicated treatments. Bar graphs of the relative fold change of CDH1 mRNA in (E) MCF-7 and (F) MDA-MB-231 cells following the indicated treatments. $\mathrm{n}=3$; a fold change $>2$ was considered to indicate a significant difference. Representative western blots revealed the upregulation of CDH1 in (G) MCF-7 and (H) MDA-MB-231 cells following the indicated treatments. Bar graphs of quantitative densitometric results revealed the upregulation of CDH1 in (I) MCF-7 and (J) MDA-MB-231 cells by the indicated treatments. Data were presented as the mean $\pm \mathrm{SD}, \mathrm{n}=3 .{ }^{*} \mathrm{P}<0.05,{ }^{* *} \mathrm{P}<0.01$ and ${ }^{* * *} \mathrm{P}<0.001 \mathrm{vs}$. the control. PEITC, phenethyl isothiocyanate; CDH1, cadherin 1; MSP, methylation-specific PCR; M, methylation; U, unmethylation; C, control. 
A

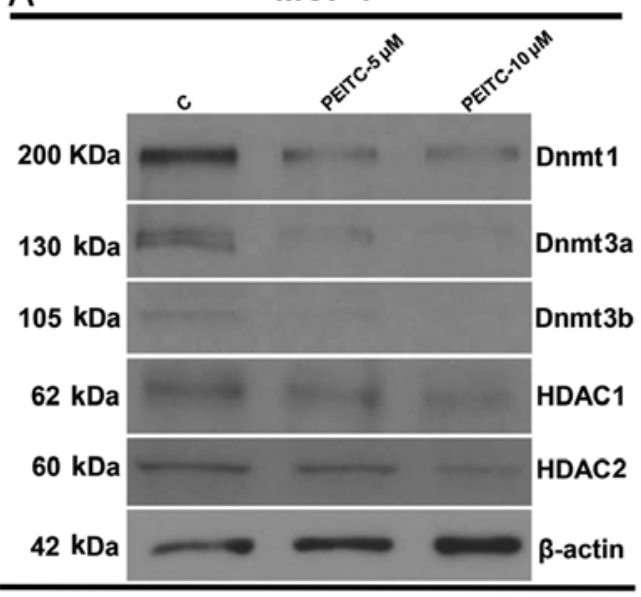

B

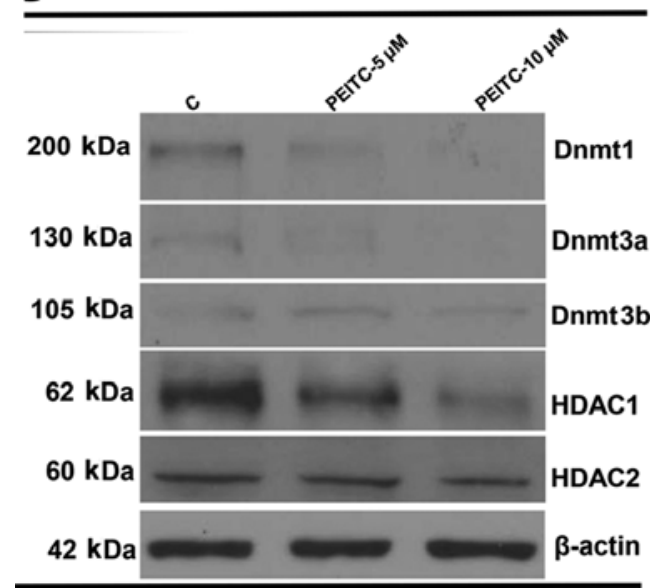

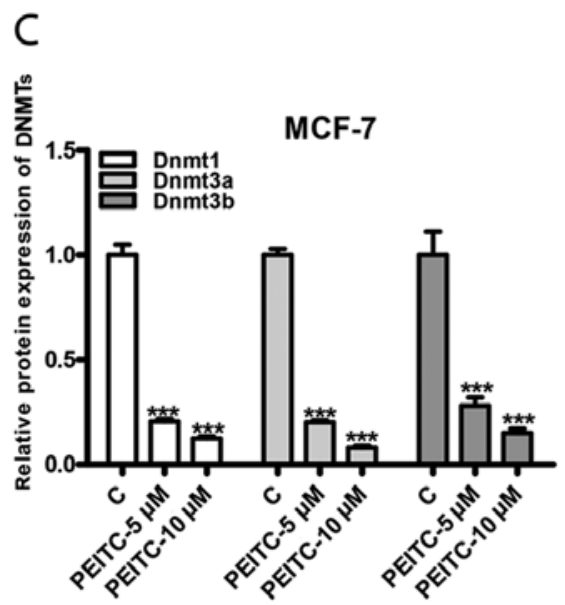
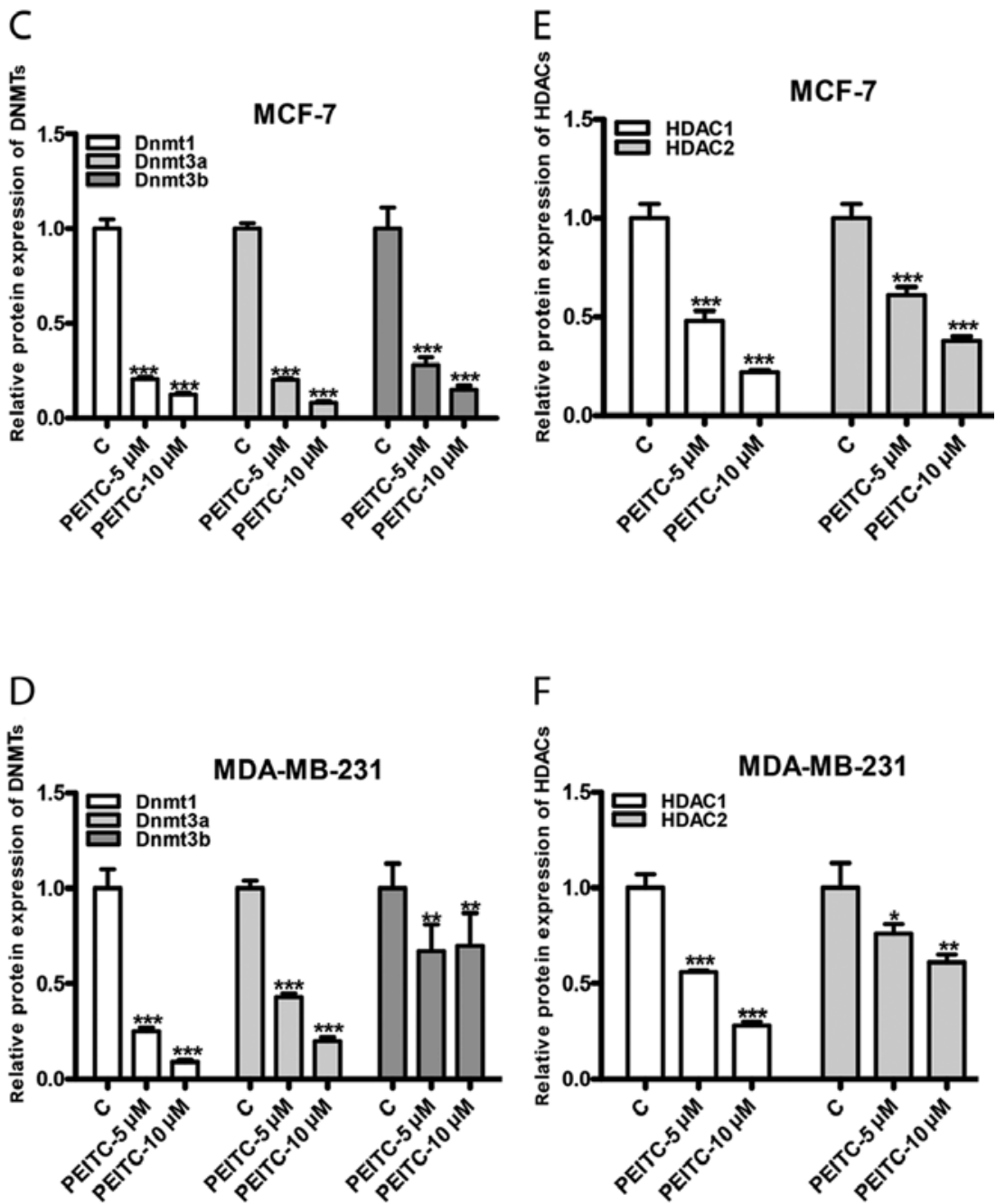

Figure 4. Effect of PEITC on DNMTs and HDACs. Representative western blots revealed the reduction in protein expression of DNMTs (Dnmt1, Dnmt3a and Dnmt3b) and HDACs (HDAC1 and HDAC2) by PEITC treatment in (A) MCF-7 and (B) MDA-MB-231 cells. Bar graphs of quantitative densitometric results indicated the downregulation of Dnmt1, Dnmt3a and Dnmt3b by PEITC in (C) MCF-7 and (D) MDA-MB-231 cells. Bar graphs of the quantitative densitometric results revealed the downregulation of HDAC1 and HDAC2 by PEITC in (E) MCF-7 and (F) MDA-MB-231 cells. Data were presented as the mean $\pm \mathrm{SD}, \mathrm{n}=3$. ${ }^{*} \mathrm{P}<0.05,{ }^{* *} \mathrm{P}<0.01$ and ${ }^{* * *} \mathrm{P}<0.001$ vs. the control. PEITC, phenethyl isothiocyanate; DNMTs; DNA methyltransferase; HDACs, histone deacetylases; C, control.

and MDA-MB-231 (Fig. 3F) cells. Similarly, CDH1 protein levels were also significantly upregulated by PEITC in MCF-7 (Fig. 3G and I) and MDA-MB-231 (Fig. 3H and J) cells. These results indicated that $\mathrm{PEITC}$ reactivated $\mathrm{CDH} 1$ by affecting epigenetic regulation.

PEITC inhibits DNMTs and HDACs. DNMTs (Dnmt1, Dnmt3a, and Dnmt3b) and HDACs (HDAC1 and HDAC2) are enzymes that catalyze the addition of a methyl group and removal of acetyl groups, respectively (19). These enzymes play crucial roles in mediating the silencing of tumor suppressor genes with tumor progression (33). To further investigate whether PEITC restored CDH1 expression via epigenetic regulation, the effects of PEITC on DNMTs and HDACs were evaluated by western blotting and quantitative densitometry. PEITC (5 and $10 \mu \mathrm{M}$ ) significantly inhibited the protein expression of DNMTs (Dnmt1, Dnmt3a and Dnmt3b) and HDACs (HDAC1 and HDAC2) in both MCF-7 (Fig. 4A, C and E) and MDA-MB231 (Fig. 4B, D and F) cells.
PEITC-reactivated CDH1 inhibits the Wnt/ $\beta$-catenin signaling pathway. Based on the epigenetic reactivation of $\mathrm{CDH} 1$ by PEITC, the underlying mechanism of $\mathrm{CDH} 1$ regulation that reduces BCSC-like properties was further explored. It is well-documented that CDH1 affects the Wnt/ $\beta$-catenin signaling pathway by binding to $\beta$-catenin at the cytoplasmic membrane. This prevents $\beta$-catenin translocation into the nuclei and formation of the $\beta$-catenin/TCF transcription factor complex (16). Previous research has also revealed that the $W n t / \beta$-catenin signaling pathway plays a pivotal role in maintaining BCSC-like properties (27). Thus, it was speculated whether PEITC-reactivated CDH1 would disrupt intracellular Wnt $/ \beta$-catenin signaling in breast cancer cells. To address this question, MCF-7 and MDA-MB-231 cells were treated with PEITC $(0,5$ and $10 \mu \mathrm{M})$ for 3 days and then Co-IP was performed to detect the ability of CDH1 and inactive $\beta$-catenin (phospho-Ser33/37) to interact. PEITC increased the amount of inactive $\beta$-catenin that co-precipitated with $\mathrm{CDH} 1$ (Fig. 5A and B). Next the effects of PEITC on Wnt/ $\beta$-catenin 
A

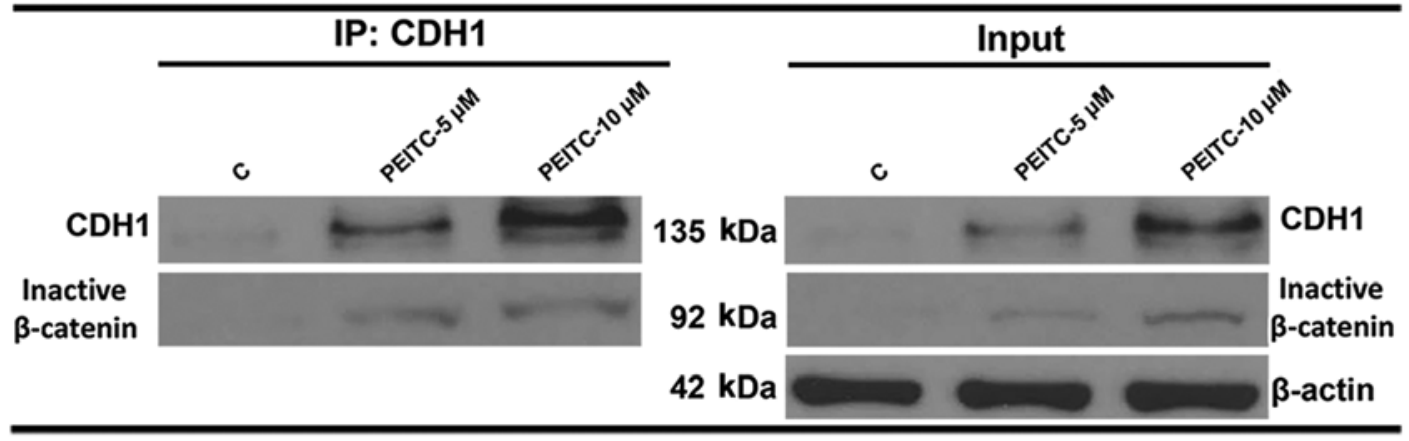

B

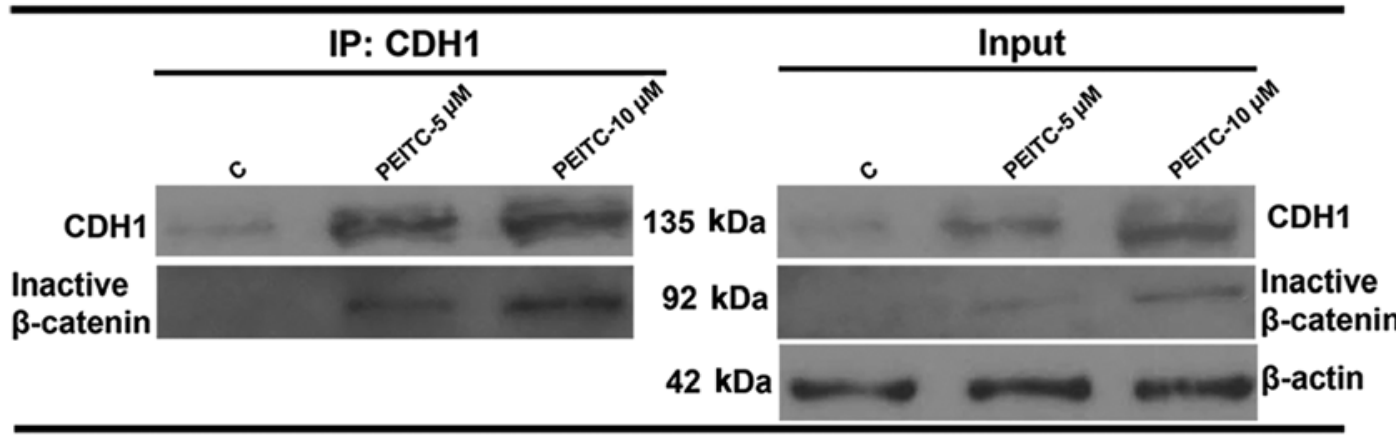

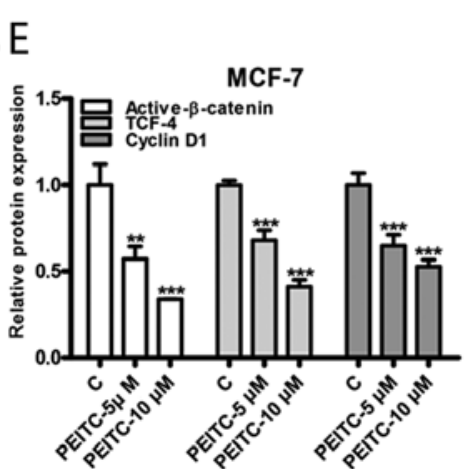
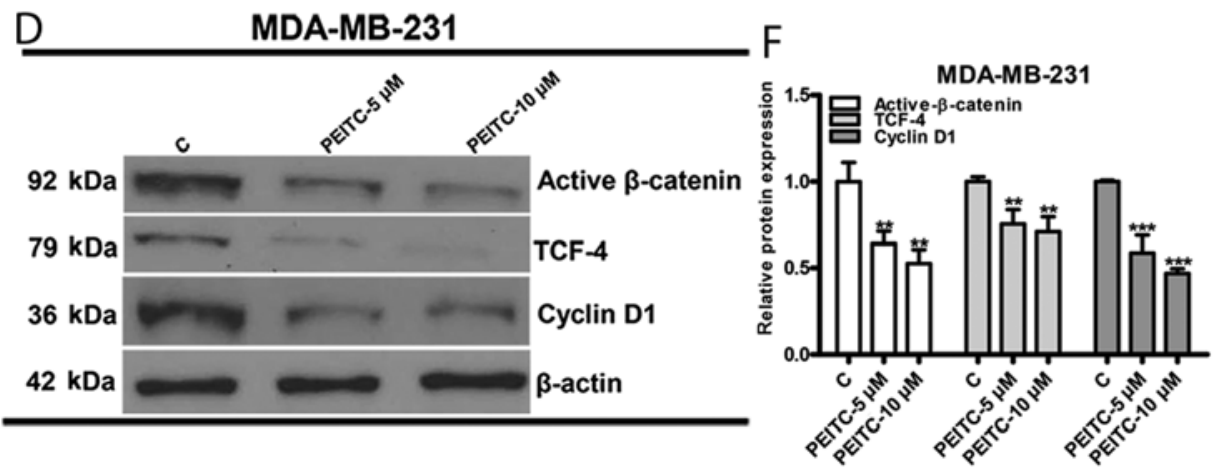

Figure 5. Effect of PEITC on the CDH1/Wnt/ $\beta$-catenin pathway. Representative Co-IP blots revealed an increased amount of the CDH1 and inactive- $\beta$-catenin (phospho-Ser33/37) complex following PEITC treatment in (A) MCF-7 and (B) MDA-MB-231 cells. Representative western blots revealed the inhibition of active $\beta$-catenin (phospho-Ser675), TCF-4 and cyclin D1 by PEITC in (C) MCF-7 and (D) MDA-MB-231 cells. Bar graphs of quantitative densitometric results revealed the downregulation of active $\beta$-catenin (phospho-Ser675), TCF-4 and cyclin D1 in (E) MCF-7 and (F) MDA-MB-231 cells by PEITC. Data were presented as the mean $\pm \mathrm{SD}, \mathrm{n}=3 .{ }^{* *} \mathrm{P}<0.01$ and ${ }^{* * *} \mathrm{P}<0.001$ vs. the control. PEITC, phenethyl isothiocyanate; $\mathrm{CDH1}$, cadherin 1; Co-IP, co-immunoprecipitation.

signaling in MCF-7 and MDA-MB-231 cells were detected by western blotting and quantitative densitometry. Active $\beta$-catenin (phosphor-Ser675) induced $\beta$-catenin accumulation in the nucleus and promoted $\beta$-catenin/TCF4 transcription activity. Cyclin D1 is a well-established downstream gene of the Wnt/ß-catenin pathway (34). Protein levels of active 


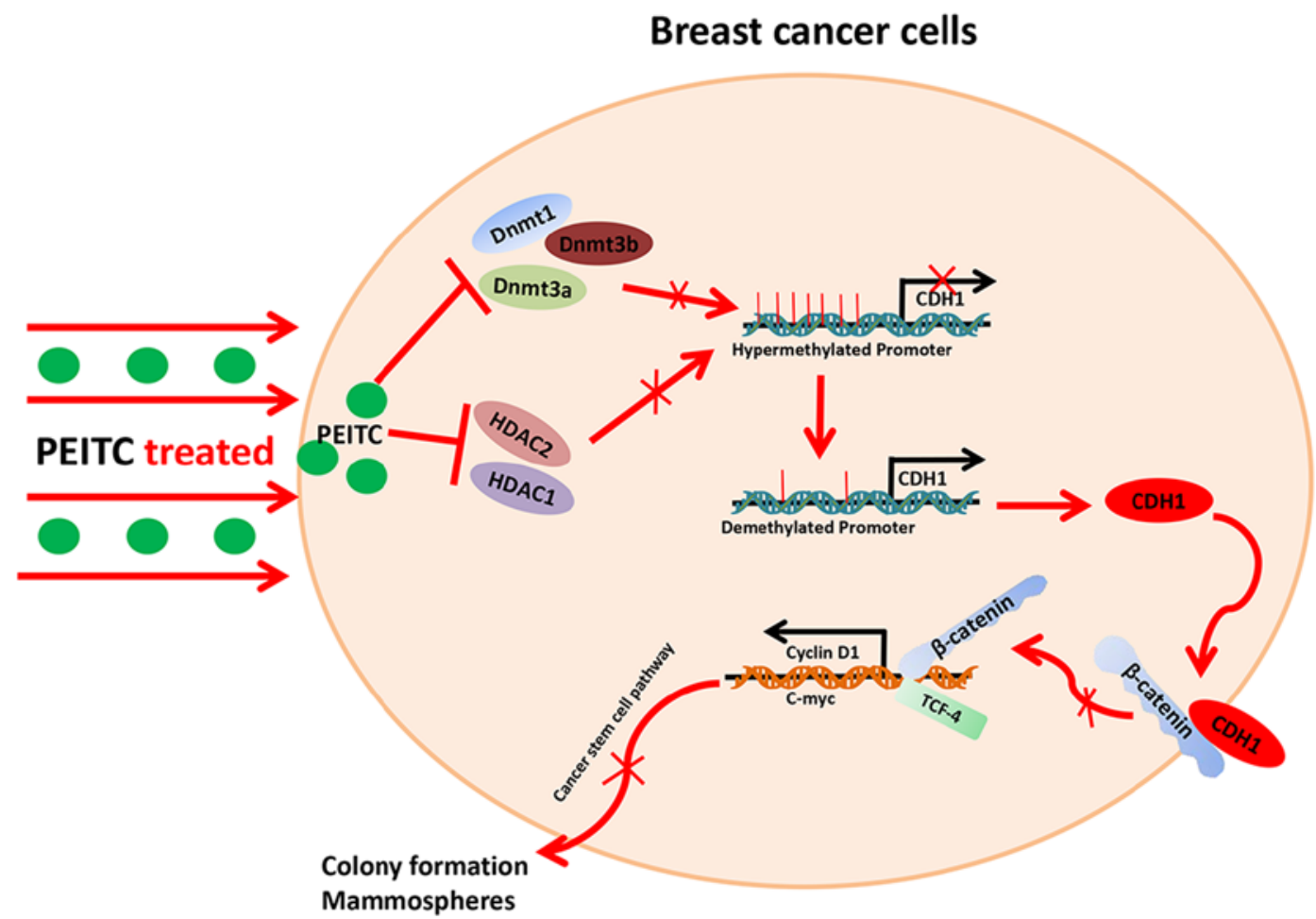

Figure 6. Schematic of the mechanism by which PEITC epigenetically reactivates CDH1 to inhibit the Wnt/ק-catenin pathway and reduces BCSC-like properties. PEITC, phenethyl isothiocyanate; CDH1, cadherin 1; BCSC, breast cancer stem cell.

$\beta$-catenin, TCF-4 and cyclin D1 were significantly decreased in MCF-7 (Fig. 5C and E) and MDA-MB-231 (Fig. 5D and F) cells following PEITC $(0,5$ and $10 \mu \mathrm{M})$ treatment for 3 days. Collectively, the data indicated that PEITC reactivated CDH1, which inhibited the Wnt/ $\beta$-catenin signaling pathway.

\section{Discussion}

Breast cancer is the most frequently diagnosed malignancy and leading cause of cancer-related deaths in women worldwide. BCSCs are considered the origin of heterogeneous breast cancer cells and are attractive prospects for therapy (27). Previous studies have identified that PEITC, a novel epigenetic regulator, exerts antitumor effects on malignant cells $(9,19)$. Previous studies have also revealed that $\mathrm{CDH} 1$, a tumor suppressor frequently silenced by promoter hypermethylation in solid tumors including breast cancer, plays a crucial role in reversing CSC properties $(16,23)$. It has also been demonstrated that PEITC has the potential to eradicate CSCs in cervical, colorectal and ovarian cancer $(13,35,36)$ as well as breast cancer cells including the aggressive subtype such as triple negative breast cancer cells $(37,38)$. However, to the best of our knowledge, no study to date, has shown the epigenetic effects of PEITC on CDH1 in BCSCs. In the present study, it was demonstrated for the first time that PEITC reduced BCSC-like properties via epigenetic reactivation of CDH1, thus inhibiting the Wnt/ $\beta$-catenin pathway (Fig. 6).

Accumulating studies have demonstrated that tumors are composed of a hodgepodge of cancer cells with diverse functions and phenotypes. As a remarkably small proportion of cancer cells, CSCs have the potential to generate self-renewal and heterogeneous tumor cell lineages that contribute to cancer initiation, metastasis, progression, therapy resistance, and tumor relapse (39). Therefore, it is critical to develop effective ways to eradicate or differentiate them during antitumor therapy. Natural products have drawn considerable attention for their marked antitumor activities (40). Recently emerging evidence indicates that natural products are promising new candidates to eliminate CSCs through multiple biological mechanisms such as targeting key signaling pathways or epigenetic regulation (41). Curcumin, a compound derived from the rhizome of turmeric, has been reported to reduce CSC-like properties by downregulating the $\mathrm{Wnt} / \beta$-catenin pathway in lung, colorectal, and breast cancer cells (42-44). Cruciferae sulforaphane (SFN), a natural compound present in cruciferous vegetables, has been revealed to inhibit nasopharyngeal carcinoma (NPC) stem cells through the DNMT1/Wnt inhibitory factor 1 (Wif1) axis (45). In the present study, we examined the effects of PEITC, also a natural bioactive compound, on breast cancer cells and revealed that it could significantly reduce BCSC-like properties in vitro. Previous research has demonstrated PEITC to function as a tumor killer by inhibiting the CD44v-xCT axis in colorectal CSCs and the Sp1 transcription factor in cervical CSCs $(46,47)$. The mechanism of PEITC on BCSC-like properties was further investigated in the present study.

Extensive studies have indicated that epigenetic alteration in cancer cells including DNA methylation, histone modifications, and chromatin remodeling maintains CSC-like properties (48). CDH1, a tumor suppressor gene, has been revealed to be transcriptionally silenced due to promoter hypermethylation during breast cancer progression (22). Previous studies have revealed that reversing CDH1 methylation could reactivate $\mathrm{CDH} 1$ expression and reduce 
CSC-associated properties $(16,23)$. Recent investigations into the use of PEITC as an epigenetic modifier have provided new insights into its anticancer effects $(19,26)$. Thus, it was hypothesized that PEITC may epigenetically regulate $\mathrm{CDH} 1$ to reduce BCSC-associated properties. By using MSP, it was observed that the $\mathrm{CDH} 1$ promoter region was hypermethylated in untreated MCF-7 and MDA-MB-231 cells, consistent with a previous study by Pradhan et al (49). However, after PEITC (5 or $10 \mu \mathrm{M})$ treatment, both MCF-7 and MDA-MB-231 cells exhibited significant demethylation of the CDH1 promoter. $\mathrm{CDH} 1$ promoter demethylation was also observed in the positive controls, 5-Aza $(2.5 \mu \mathrm{M})$ and TSA $(0.5 \mu \mathrm{M})$ treated-cells. It was confirmed by qPCR and western blotting that PEITC could restore CDH1 mRNA and protein levels in both MCF-7 and MDA-MB-231 cells. These results are similar to several other studies that have revealed reactivation of CDH1 by epigenetic reagents such as epigallocatechin-gallate (EGCG) and Bisphenol S (BPS) (50,51). Notably, although the consistent biological behavior of epigenetic regulations in breast cancer cells between PEITC-treated groups and positive controls (2.5 $\mu \mathrm{M} 5$-Aza and $0.5 \mu \mathrm{M}$ TSA) were observed, it still could not be excluded whether there are other mechanisms involved in PEITC reactivation of $\mathrm{CDH} 1$ in addition to the epigenetic effects which played a major role. Moreover, while the demethylating effects of the positive controls $(2.5 \mu \mathrm{M} 5$-Aza and $0.5 \mu \mathrm{M}$ TSA) were stronger than that of $10 \mu \mathrm{M}$ PEITC, CDH1 mRNA and protein levels were lower, suggesting that PEITC exerts a greater effect on either histone modification or chromatin relaxation. Previous research has characterized the histone modification effects of PEITC to a certain degree (48), but further study is required to elucidate this observed phenomenon. DNA methylation and histone deacetylation, mediated by DNMTs and HDACs, respectively, are the most common epigenetic events that occur with tumor progression and lead to the silencing of tumor suppressor genes. Thus, the effects of PEITC on DNMTs and HDACs were further examined. It was revealed that PEITC (5 or $10 \mu \mathrm{M})$ could significantly reduce DNMT and HDAC protein levels. However, the mechanism by which PEITC inhibits DNMTs and HDACs remains unclear, requiring further study.

Numerous studies have shown that the Wnt/ $\beta$-catenin pathway is constitutively active in the development of breast cancer and plays a role in regulating the self-renewal of BCSCs $(23,27)$. A previous study revealed that the epigenetic reactivation of $\mathrm{CDH} 1$ could promote assembly of the $\mathrm{CDH} 1 / \beta$-catenin complex in the cytoplasmic membrane and prevent $\beta$-catenin translocation into the nucleus, thereby inactivating the Wnt/ $\beta$-catenin pathway and suppressing carcinoma cell stemness (16). In the present study, after identifying that PEITC could epigenetically restore CDH1, the effects of PEITC on the CDH1/ $\beta$-catenin complex and Wnt $/ \beta$-catenin pathway were assessed. Co-IP and western blotting indicated that PEITC significantly increased the amount of inactive $\beta$-catenin (phospho-Ser33/37) that co-precipitated with CDH1. TCF-4 is a key effector in CSC-like trait maintenance by forming the $\beta$-catenin/TCF4 complex, which transcriptionally activates downstream factors such as cyclin D1 in the Wnt pathway $(34,52)$. The present study revealed that PEITC (5 or $10 \mu \mathrm{M})$ significantly decreased the protein expression levels of active $\beta$-catenin (phospho-Ser675), TCF-4 and cyclin D1.
A previous study revealed that PEITC could inhibit the Wnt/ $\beta$-catenin pathway to eliminate colorectal CSCs (13). However, the present study elucidated for the first time that epigenetic regulation by PEITC reactivated $\mathrm{CDH} 1$, which inhibited the Wnt/ $\beta$-catenin pathway and reduced BCSC-like properties.

There are some limitations to the present study. It is well known that the dose-dependent effects of drugs and the optimal effective concentration revealed by in vitro experiments are useful for further development of promising anticancer drugs. However, we only used 2 sublethal doses of PEITC, 5 and $10 \mu \mathrm{M}$, to perform the experiments in the present study. Thus, we cannot rigorously conclude that the effects and mechanism of PEITC function to reduce BCSC-like properties in a dosedependent manner or identify the optimal concentration of PEITC. In addition, due to limitations of the experimental conditions at our laboratory and some objective reasons such as the COVID-19 pandemic, we did not isolate special BCSC subtypes such as $\mathrm{CD} 44^{+} / \mathrm{CD} 24^{-}$by flow cytometry to further evaluate and characterize the function and mechanism of PEITC in eradicating BCSCs in a nude mouse tumor xenograft model, which needs to be conducted in the future.

In conclusion, the present study revealed a novel epigenetic regulation-mediated mechanism by which PEITC reduced CSC-like properties in breast cancer cells. It was revealed that PEITC significantly inhibited colony and tumor sphere formation abilities and reduced the expression of CSC-associated protein markers via epigenetic reactivation of CDH1. Inhibitory effects of PEITC on the expression of DNMTs and HDACs resulted in demethylation of the CDH1 promoter region. $\mathrm{CDH} 1$ then inhibited the $\mathrm{Wnt} / \beta$-catenin pathway and formation of the $\beta$-catenin/TCF transcription factor complex to suppress CSC-like properties. The present findings suggest that PEITC is a potential natural product that can be further developed for the eradication of breast cancer stem cells.

\section{Acknowledgments}

Not applicable.

\section{Funding}

The present study was supported from the Natural Science Foundation of Hunan Province (grant no. 2019JJ50542), the Science and Technology program of Hunan Health Commission (grant no. 20201978), and the China Scholarship Council (grant no. 201808430085).

\section{Availability of data and materials}

The datasets used during the present study are available from the corresponding author upon reasonable request.

\section{Authors' contributions}

$\mathrm{TZ}$ conceived and designed the experiments. TZ and $\mathrm{WZ}$ performed the experiments. TZ and MH analyzed the data. TZ wrote the manuscript. TZ and $\mathrm{MH}$ revised the manuscript. All authors read and approved the final manuscript. 


\section{Ethics approval and consent to participate}

Not applicable.

\section{Patient consent for publication}

Not applicable.

\section{Competing interests}

The authors declare that they have no competing interests.

\section{References}

1. Bray F, Ferlay J, Soerjomataram I, Siegel RL, Torre LA and Jemal A: Global cancer statistics 2018: GLOBOCAN estimates of incidence and mortality worldwide for 36 cancers in 185 countries. CA Cancer J Clin 68: 394-424, 2018.

2. Chu D and Lu J: Novel therapies in breast cancer: What is new from ASCO 2008. J Hematol Oncol 1: 16, 2008

3. Chinese Anti-Cancer Association, Committee of Breast Cancer Society. Chinese expert consensus on the clinical diagnosis and treatment of advanced breast carcinoma(2018). Zhonghua Zhong Liu Za Zhi 40(9): 703-713, 2018 (In Chinese).

4. Luo M, Clouthier SG, Deol Y, Liu S, Nagrath S, Azizi E and Wicha MS: Breast cancer stem cells: Current advances and clinical implications. Methods Mol Biol 1293: 1-49, 2015.

5. Yang F, Xu J, Tang L and Guan X: Breast cancer stem cell: The roles and therapeutic implications. Cell Mol Life Sci 74: 951-966, 2017.

6. Bunting KD: ABC transporters as phenotypic markers and functional regulators of stem cells. Stem Cells 20: 11-20, 2002.

7. Liu Y, Burness ML, Martin-Trevino R, Guy J, Bai S, Harouaka R, Brooks MD, Shang L, Fox A, Luther TK, et al: RAD51 mediates resistance of cancer stem cells to PARP inhibition in triplenegative breast cancer. Clin Cancer Res 23: 514-522, 2017.

8. Butti R, Gunasekaran VP, Kumar TVS, Banerjee P and Kundu GC: Breast cancer stem cells: Biology and therapeutic implications. Int J Biochem Cell Biol 107: 38-52, 2019.

9. Gupta P, Wright SE, Kim SH and Srivastava SK: Phenethyl isothiocyanate: A comprehensive review of anti-cancer mechanisms. Biochim Biophys Acta 1846: 405-424, 2014.

10. Trachootham D, Zhang H, Zhang W, Feng L, Du M, Zhou Y, Chen Z, Pelicano H, Plunkett W, Wierda WG, et al: Effective elimination of fludarabine-resistant CLL cells by PEITC through a redox-mediated mechanism. Blood 112: 1912-1922, 2008.

11. Trachootham D, Zhou Y, Zhang H, Demizu Y, Chen Z, Pelicano H, Chiao PJ, Achanta G, Arlinghaus RB, Liu J, et al: Selective killing of oncogenically transformed cells through a ROS-mediated mechanism by beta-phenylethyl isothiocyanate. Cancer Cell 10: 241-252, 2006

12. Zhang T, Shao Y, Chu TY, Huang HS, Liou YL, Li Q and Zhou H: MiR-135a and MRP1 play pivotal roles in the selective lethality of phenethyl isothiocyanate to malignant glioma cells. Am J Cancer Res 6: 957-972, 2016.

13. Chen Y, Li Y, Wang XQ, Meng Y,Zhang Q, Zhu JY, Chen JQ, Cao WS, Wang XQ, Xie CF, et al: Phenethyl isothiocyanate inhibits colorectal cancer stem cells by suppressing Wnt $/ \beta$-catenin pathway. Phytother Res 32: 2447-2455, 2018.

14. Liou YL, Zhang TL, Yan T, Yeh CT, Kang YN, Cao L, Wu N, Chang CF, Wang HJ, Yen C, et al: Combined clinical and genetic testing algorithm for cervical cancer diagnosis. Clin Epigenetics 8: 66,2016

15. Pasculli B, Barbano R and Parrella P: Epigenetics of breast cancer: Biology and clinical implication in the era of precision medicine. Semin Cancer Biol 51: 22-35, 2018.

16. Liu T, Wu X, Chen T, Luo Z and Hu X: Downregulation of DNMT3A by miR-708-5p inhibits lung cancer stem cell-like phenotypes through repressing $\mathrm{Wnt} / \beta$-catenin signaling. Clin Cancer Res 24: 1748-1760, 2018.

17. Yu F, Jiao Y, Zhu Y, Wang Y, Zhu J, Cui X, Liu Y, He Y, Park EY, Zhang H, et al: MicroRNA 34c gene down-regulation via DNA methylation promotes self-renewal and epithelial-mesenchymal transition in breast tumor-initiating cells. J Biol Chem 287: 465-473, 2012.
18. Sun L, Mathews LA, Cabarcas SM, Zhang X, Yang A, Zhang Y, Young MR, Klarmann KD, Keller JR and Farrar WL: Epigenetic regulation of SOX 9 by the $\mathrm{NF}-\kappa \mathrm{B}$ signaling pathway in pancreatic cancer stem cells. Stem Cells 31: 1454-1466, 2013.

19. Boyanapalli SS, Li W, Fuentes F, Guo Y, Ramirez CN, Gonzalez XP, Pung D and Kong AN: Epigenetic reactivation of RASSF1A by phenethyl isothiocyanate (PEITC) and promotion of apoptosis in LNCaP cells. Pharmacol Res 114: 175-184, 2016.

20. Gupta R, Bhatt LK and Momin M: Potent antitumor activity of Laccaic acid and Phenethyl isothiocyanate combination in colorectal cancer via dual inhibition of DNA methyltransferase-1 and Histone deacetylase-1. Toxicol Appl Pharmacol 377: 114631, 2019.

21. Berx G and van Roy F: Involvement of members of the cadherin superfamily in cancer. Cold Spring Harb Perspect Biol 1: a003129, 2009.

22. Shinozaki M, Hoon DS, Giuliano AE, Hansen NM, Wang HJ, Turner R and Taback B: Distinct hypermethylation profile of primary breast cancer is associated with sentinel lymph node metastasis. Clin Cancer Res 11: 2156-2162, 2005.

23. Ma F, Li W, Liu C, Li W, Yu H, Lei B, Ren Y, Li Z, Pang D and Qian C: MiR-23a promotes TGF- $\beta 1$-induced EMT and tumor metastasis in breast cancer cells by directly targeting CDH1 and activating Wnt/ß-catenin signaling. Oncotarget 8: 69538-69550, 2017.

24. Huang R, Ding P and Yang F: Clinicopathological significance and potential drug target of CDH1 in breast cancer: A metaanalysis and literature review. Drug Des Devel Ther 9: 5277-5285, 2015.

25. Livak KJ and Schmittgen TD: Analysis of relative gene expression data using real-time quantitative PCR and the 2(-Delta Delta C(T)) Method. Methods 25: 402-408, 2001.

26. Park JE, Sun Y, Lim SK, Tam JP, Dekker M, Chen H and Sze SK Dietary phytochemical PEITC restricts tumor development via modulation of epigenetic writers and erasers. Sci Rep 7: 40569, 2017.

27. Zheng A, Song X, Zhang L, Zhao L, Mao X, Wei M and Jin F: Long non-coding RNA LUCAT1/miR-5582-3p/TCF7L2 axis regulates breast cancer stemness via Wnt/ $\beta$-catenin pathway. J Exp Clin Cancer Res 38: 305, 2019.

28. Lawson DA, Bhakta NR, Kessenbrock K, Prummel KD, Yu Y, Takai K, Zhou A, Eyob H, Balakrishnan S, Wang CY, et al: Single-cell analysis reveals a stem-cell program in human metastatic breast cancer cells. Nature 526: 131-135, 2015.

29. Tsang JY, Huang YH, Luo MH, Ni YB, Chan SK, Lui PC, Yu AM, Tan PH and Tse GM: Cancer stem cell markers are associated with adverse biomarker profiles and molecular subtypes of breast cancer. Breast Cancer Res Treat 136: 407-417, 2012.

30. Almozyan S, Colak D, Mansour F, Alaiya A, Al-Harazi O, Qattan A, Al-Mohanna F, Al-Alwan M and Ghebeh H: PD-L1 promotes OCT4 and Nanog expression in breast cancer stem cells by sustaining PI3K/AKT pathway activation. Int J Cancer 141: 1402-1412, 2017.

31. Das S, Mukherjee P, Chatterjee R, Jamal Z and Chatterji U: Enhancing chemosensitivity of breast cancer stem cells by downregulating SOX2 and ABCG2 using wedelolactone-encapsulated nanoparticles. Mol Cancer Ther 18: 680-692, 2019.

32. Matsumura T, Makino R and Mitamura K: Frequent downregulation of E-cadherin by genetic and epigenetic changes in the malignant progression of hepatocellular carcinomas. Clin Cancer Res 7: 594-599, 2001

33. Gelato KA, Shaikhibrahim Z, Ocker M and Haendler B: Targeting epigenetic regulators for cancer therapy: Modulation of bromodomain proteins, methyltransferases, demethylases, and microRNAs. Expert Opin Ther Targets 20: 783-799, 2016.

34. Lecarpentier Y, Schussler O, Hébert JL and Vallée A: Multiple targets of the canonical WNT/ $\beta$-catenin signaling in cancers. Front Oncol 9: 1248, 2019.

35. Wang D, Upadhyaya B, Liu Y, Knudsen D and Dey M: Phenethyl isothiocyanate upregulates death receptors 4 and 5 and inhibits proliferation in human cancer stem-like cells. BMC Cancer 14: $591,2014$.

36. Koschorke A, Faraci S, Giani D, Chiodoni C, Iorio E, Canese R, Colombo MP, Lamolinara A, Iezzi M, Ladomery M, et al: Phenethyl isothiocyanate hampers growth and progression of HER2-positive breast and ovarian carcinoma by targeting their stem cell compartment. Cell Oncol (Dordr) 42: 815-828, 2019.

37. Sarkar R, Mukherjee S, Biswas J and Roy M: Phenethyl isothiocyanate, by virtue of its antioxidant activity, inhibits invasiveness and metastatic potential of breast cancer cells: HIF-1 $\alpha$ as a putative target. Free Radic Res 50: 84-100, 2016. 
38. Gupta P, Adkins C, Lockman P and Srivastava SK: Metastasis of breast tumor cells to brain is suppressed by phenethyl isothiocyanate in a novel in vivo metastasis model. PLoS One 8: e67278, 2013.

39. Henkin RI: Clinical and therapeutic implications of cancer stem cells. N Engl J Med 381: e19, 2019.

40. Pratheeshkumar P, Sreekala C, Zhang Z, Budhraja A, Ding S, Son YO, Wang X, Hitron A, Hyun-Jung K, Wang L, et al: Cancer prevention with promising natural products: Mechanisms of action and molecular targets. Anticancer Agents Med Chem 12: 1159-1184, 2012.

41. Palermo R, Ghirga F, Piccioni MG, Bernardi F, Zhdanovskaya N, Infante $\mathrm{P}$ and Mori $\mathrm{M}$ : Natural products inspired modulators of cancer stem cells-specific signaling pathways Notch and Hedgehog. Curr Pharm Des 24: 4251-4269, 2018.

42. Zhu JY, Yang X, Chen Y, Jiang Y, Wang SJ, Li Y, Wang XQ, Meng Y,Zhu MM, Ma X, et al: Curcumin suppresses lung cancer stem cells via inhibiting Wnt/ $\beta$-catenin and aonic Hedgehog pathways. Phytother Res 31: 680-688, 2017.

43. Huang YT, Lin YW, Chiu HM and Chiang BH: Curcumin induces apoptosis of colorectal cancer stem cells by coupling with CD44 marker. J Agric Food Chem 64: 2247-2253, 2016.

44. Dandawate PR, Subramaniam D, Jensen RA and Anant S: Targeting cancer stem cells and signaling pathways by phytochemicals: Novel approach for breast cancer therapy. Semin Cancer Biol 40-41: 192-208, 2016.

45. Chen L, Chan LS, Lung HL, Yip TTC, Ngan RKC, Wong JWC, Lo KW, Ng WT, Lee AWM, Tsao GSW, et al: Crucifera sulforaphane (SFN) inhibits the growth of nasopharyngeal carcinoma through DNA methyltransferase 1 (DNMT1)/Wnt inhibitory factor 1 (WIF1) axis. Phytomedicine 63: 153058, 2019.
46. Ju HQ, Lu YX, Chen DL, Tian T, Mo HY, Wei XL, Liao JW, Wang F, Zeng ZL, Pelicano H, et al: Redox regulation of stem-like cells though the CD44v-xCT axis in colorectal cancer: mechanisms and therapeutic implications. Theranostics 6: 1160-1175, 2016

47. Upadhyaya B, Liu Y and Dey M: Phenethyl isothiocyanate exposure promotes oxidative stress and suppresses Sp1 transcription Factor in Cancer Stem Cells. Int J Mol Sci 20: 20, 2019.

48. Feinberg AP, Koldobskiy MA and Göndör A: Epigenetic modulators, modifiers and mediators in cancer aetiology and progression. Nat Rev Genet 17: 284-299, 2016.

49. Pradhan N, Parbin S, Kar S, Das L, Kirtana R, Suma Seshadri G, Sengupta D, Deb M, Kausar C and Patra SK: Epigenetic silencing of genes enhanced by collective role of reactive oxygen species and MAPK signaling downstream ERK/Snail axis: Ectopic application of hydrogen peroxide repress CDH1 gene by enhanced DNA methyltransferase activity in human breast cancer. Biochim Biophys Acta Mol Basis Dis 1865: 1651-1665, 2019.

50. Khan MA, Hussain A, Sundaram MK, Alalami U, Gunasekera D, Ramesh L, Hamza A and Quraishi U: (-)-Epigallocatechin-3gallate reverses the expression of various tumor-suppressor genes by inhibiting DNA methyltransferases and histone deacetylases in human cervical cancer cells. Oncol Rep 33: 1976-1984, 2015.

51. Huang W, Zhao C, Zhong H, Zhang S, Xia Y and Cai Z: Bisphenol $S$ induced epigenetic and transcriptional changes in human breast cancer cell line MCF-7. Environ Pollut 246: 697-703, 2019.

52. Lv YF, Dai H, Yan GN, Meng G, Zhang X and Guo QN: Downregulation of tumor suppressing STF cDNA 3 promotes epithelial-mesenchymal transition and tumor metastasis of osteosarcoma by the Wnt/GSK-3 $\beta / \beta$-catenin/Snail signaling pathway. Cancer Lett 373: 164-173, 2016. 